\title{
Bioactive Silver-Organic Networks Assembled from 1,3,5-Triaza-7-Phosphaadamantane and Flexible Cyclohexanecarboxylate Blocks
}

\author{
Sabina W. Jaros, ${ }^{\dagger}$ M. Fátima C. Guedes da Silva, ${ }^{*}{ }^{\dagger}$ Jarosław Król, ${ }^{\#}$ M. Conceição Oliveira, ${ }^{\dagger}$ Piotr \\ Smoleński, ${ }^{*}{ }^{\ddagger}$ Armando J. L. Pombeiro, ${ }^{\dagger}$ and Alexander M. Kirillov ${ }^{*}, \dagger$ \\ ${ }^{\dagger}$ Centro de Química Estrutural, Complexo I, Instituto Superior Técnico, Universidade de Lisboa, Av. Rovisco \\ Pais, 1049-001 Lisbon, Portugal, "Department of Pathology, Wrockaw University of Environmental and Life \\ Sciences, ul. Norwida 31, 50-375 Wroctaw, Poland, ${ }^{+}$Faculty of Chemistry, University of Wrockaw, ul. F. Joliot- \\ Curie 14, 50-383, Wroctaw, Poland. \\ *To whom correspondence should be addressed. E-mail: kirillov@ist.utl.pt, fatima.guedes@ist.utl.pt, \\ piotr.smolenski@chem.uni.wroc.pl; Phone: +351 218417178.
}

\section{Supporting Information (SI)}

Supporting Information contains additional ESI-MS/MS description and plots of compound 2 (Figures S1, S2), proposed mechanism of crystal growth (Scheme S1), PXRD patterns (Figures S3-S5) and TGA curves (Figures S6-S8). This material is available free of charge via the Internet at http://pubs.acs.org. 


\section{Additional Discussion}

ESI-MS(+) analysis of the crystallization process of 2. ESI-MS monitoring of the initial step of crystallization process of $\mathbf{2}$ discloses several positively charged species; most of them were identified. The most abundant species in all measurements belong to $\left[\operatorname{Ag}(\mathrm{PTA})_{2}\right]^{+}$ ions at $m / z$ 421. The ESI-MS ${ }^{\mathrm{n}}$ experiments of this ion display successive cleavage of adamantane cage, as described previously. ${ }^{35}$ Other sets of isotopic clusters displaying a characteristic distribution of silver-containing species were identified and divided into two main groups. These correspond to complex fragments expected in solution, namely $[\operatorname{Ag}(\mathrm{PTA})]^{+}\left(\mathrm{m} / \mathrm{z}\right.$ 264), $\left[\mathrm{Ag}_{2}(\mathrm{PTA})_{2}(\mathrm{Hchdc})\right]^{+}\left(\mathrm{m} / \mathrm{z}\right.$ 701), $\left[\mathrm{Ag}_{3}(\mathrm{PTA})_{3}(\mathrm{chdc})\right]^{+}(\mathrm{m} / \mathrm{z}$ 964), $\left[\mathrm{Ag}_{4}(\mathrm{PTA})_{2}(\mathrm{Hchdc})(\mathrm{chdc})\right]^{+} \quad(m / z \quad 1087), \quad\left[\mathrm{Ag}_{4}(\mathrm{PTA})_{3}(\mathrm{Hchdc})(\mathrm{chdc})\right]^{+} \quad(m / z \quad 1244), \quad$ and methanol, water and ammonia adducts, including $\left[\mathrm{Ag}(\mathrm{PTA})\left(\mathrm{NH}_{3}\right)\right]^{+}(m / z \quad 281)$, $\left[\mathrm{Ag}(\mathrm{PTA})\left(\mathrm{CH}_{3} \mathrm{OH}\right)\right]^{+}\left(\mathrm{m} / z\right.$ 296), $[\mathrm{Ag}(\mathrm{PTA})(\mathrm{PTA}-\mathrm{H})(\mathrm{OH})]^{+}\left(\mathrm{m} / z\right.$ 437), $\left[\mathrm{Ag}(\mathrm{PTA})_{2}\left(\mathrm{CH}_{3} \mathrm{OH}\right)\right]^{+}$ $(m / z \quad 453), \quad\left[\mathrm{Ag}_{2}(\mathrm{PTA})_{2}(\mathrm{Hchdc})\left(\mathrm{H}_{2} \mathrm{O}\right)_{4}\left(\mathrm{NH}_{3}\right)\right]^{+} \quad(m / z \quad 790), \quad$ and $\left[\mathrm{Ag}_{2}(\mathrm{PTA})_{2}(\mathrm{Hchdc})\left(\mathrm{CH}_{3} \mathrm{OH}\right)_{2}\left(\mathrm{H}_{2} \mathrm{O}\right)_{5}\right]^{+}(\mathrm{m} / z$ 855). Additional adducts formed with residual acetonitrile were also observed, namely peaks $\mathrm{m} / \mathrm{z} 305$ and 605 assigned to $\left[\mathrm{Ag}(\mathrm{PTA})\left(\mathrm{CH}_{3} \mathrm{CN}\right)\right]^{+}$and $\left[\mathrm{Ag}_{2}(\mathrm{PTA})_{2}\left(\mathrm{CH}_{3} \mathrm{CN}\right)(\mathrm{OH})\left(\mathrm{NH}_{3}\right)\right]^{+}$, respectively.

For further characterization of these complex fragments, all the isotopic clusters were isolated for CID experiments in tandem mass spectrometric analysis. MS/MS fragmentation of $\left[\mathrm{Ag}_{2}(\mathrm{PTA})_{2}(\mathrm{Hchdc})\right]^{+},\left[\mathrm{Ag}_{3}(\mathrm{PTA})_{3}(\mathrm{chdc})\right]^{+}$, and $\left[\mathrm{Ag}_{4}(\mathrm{PTA})_{2}(\mathrm{Hchdc})(\mathrm{chdc})\right]^{+}$ions occur mainly via loss of a PTA molecule to give $\left[\mathrm{Ag}_{2}(\mathrm{PTA})(\mathrm{Hchdc})\right]^{+}(\mathrm{m} / \mathrm{z} 544)$, $\left[\mathrm{Ag}_{3}(\mathrm{PTA})_{2}(\mathrm{chdc})\right]^{+} \quad\left(\mathrm{m} / \mathrm{z}\right.$ 807), and $\left[\mathrm{Ag}_{4}(\mathrm{PTA})(\mathrm{Hchdc})(\mathrm{chdc})\right]^{+} \quad(\mathrm{m} / \mathrm{z} \quad 930)$ species, respectively. It is surprising that further dissociation of peaks at $m / z 808$ and 930 proceeds only via a consecutive elimination of a PTA molecule, what indicates a lower stability of species with higher molecular mass and suggests the $N$-coordination of this aminophosphine ligand (Figure S1a and b). The consecutive fragmentation of complexes species with higher masses leads to a product ion at $m / z 323$ assigned to $\left[\mathrm{Ag}_{3}\right]^{+}$, as shown in $\mathrm{MS}^{4}$ spectrum of $\left[\mathrm{Ag}_{3}(\mathrm{PTA})_{3}(\mathrm{chdc})\right]^{+}$at $\mathrm{m} / z 964$ (Figure S1b). The ESI-MS ${ }^{2}$ characterization of the solvated complex species revealed nearly the same elimination pathway with the loss of PTA, as well as further $\mathrm{MS}^{3}$ dissociation generating a group of peaks due to successive fragmentation of PTA moiety.

Additional Comments on PXRD Analysis of 1-3. The Figures S3-S5 show the powder X-ray diffraction (PXRD) data for the bulk products 1-3 together with the simulated patterns 
obtained from the respective single crystal X-ray diffraction data. The experimental patterns were typically recorded after two weeks storage of the samples (in air and in the presence of some light). For $\mathbf{2}$ and $\mathbf{3}$, the experimental patterns show rather good matching with the calculated ones, although a partial loss of crystallinity and slight shift of some signals has been observed in $\mathbf{3}$, most likely due to the loss of crystallization water and/or partial lightinduced degradation. The experimental pattern of $\mathbf{1}$ shows deviations from the simulated one, most likely due to loss (or varying content) of co-crystallized cyclohexanecarboxylic acid.
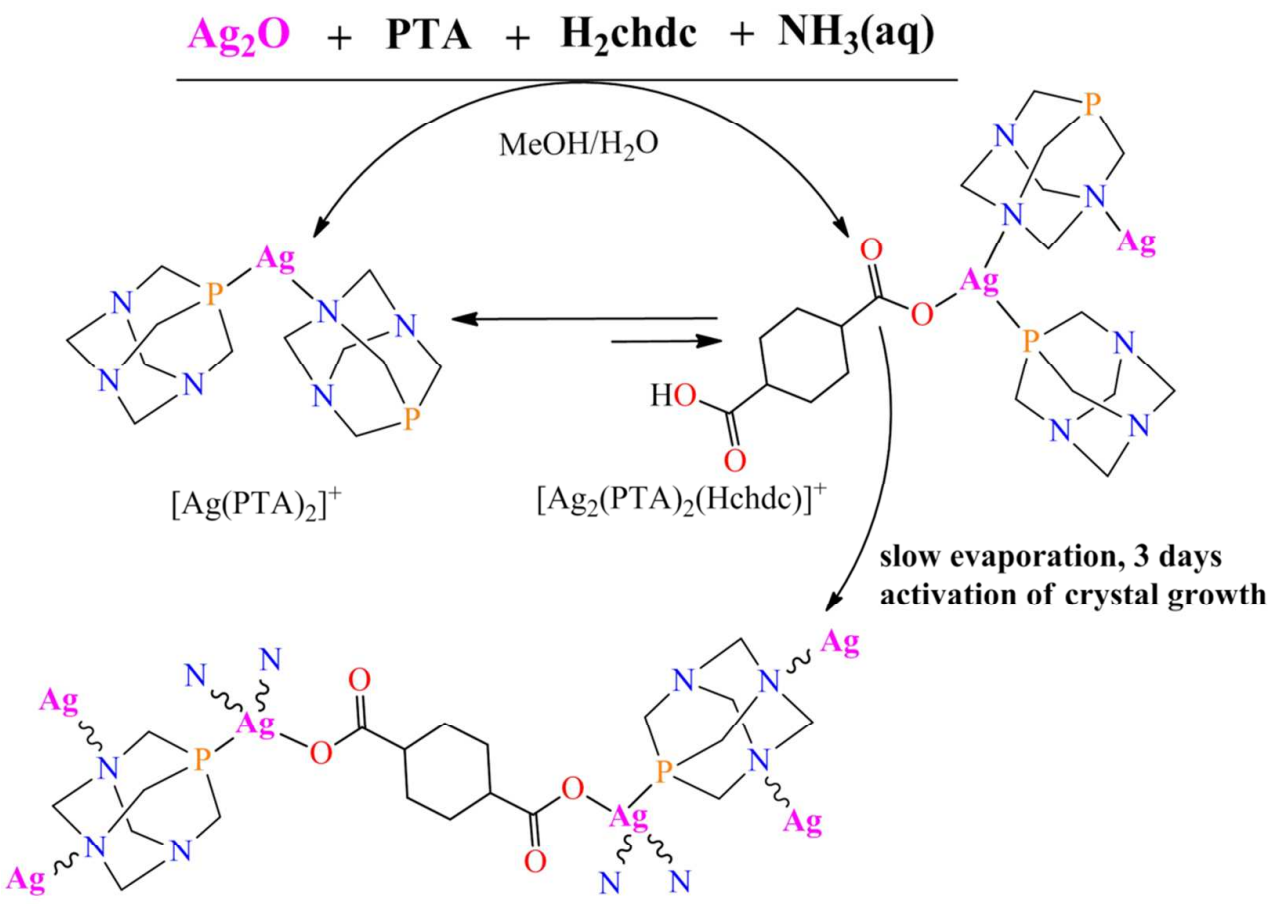

$\left[\operatorname{Ag}_{2}\left(\mu_{3}-\mathrm{PTA}\right)_{2}\left(\mu_{2}-\mathrm{chdc}\right)\right]_{\mathrm{n}}$

Scheme S1. Proposed mechanism of crystal growth for compound 2. 

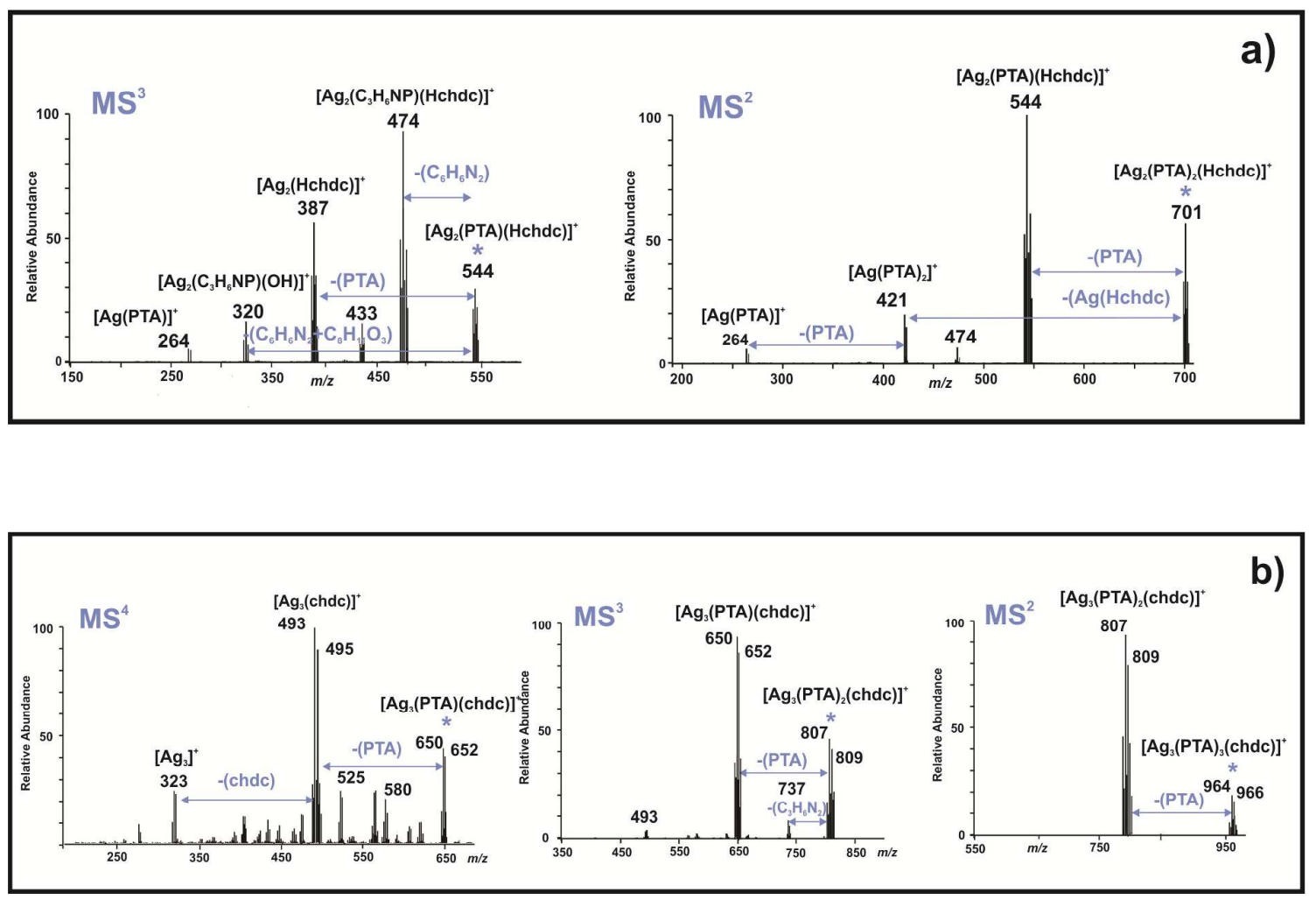

Figure S1. Positive mode ESI tandem mass spectra of a post-reaction mixture of 2: a) $\mathrm{MS}^{\mathrm{n}}$ (n $=2,3)$ spectra of the precursor ion $\left[\mathrm{Ag}_{2}(\mathrm{PTA})_{2}(\mathrm{Hchdc})\right]^{+} \mathrm{m} / z \mathrm{z}$; $;$ b) $\mathrm{MS}^{\mathrm{n}}(\mathrm{n}=2-4)$ spectra of the precursor ion $\left[\mathrm{Ag}_{3}(\mathrm{PTA})_{3}(\mathrm{chdc})\right]^{+} \mathrm{m} / z 964$.

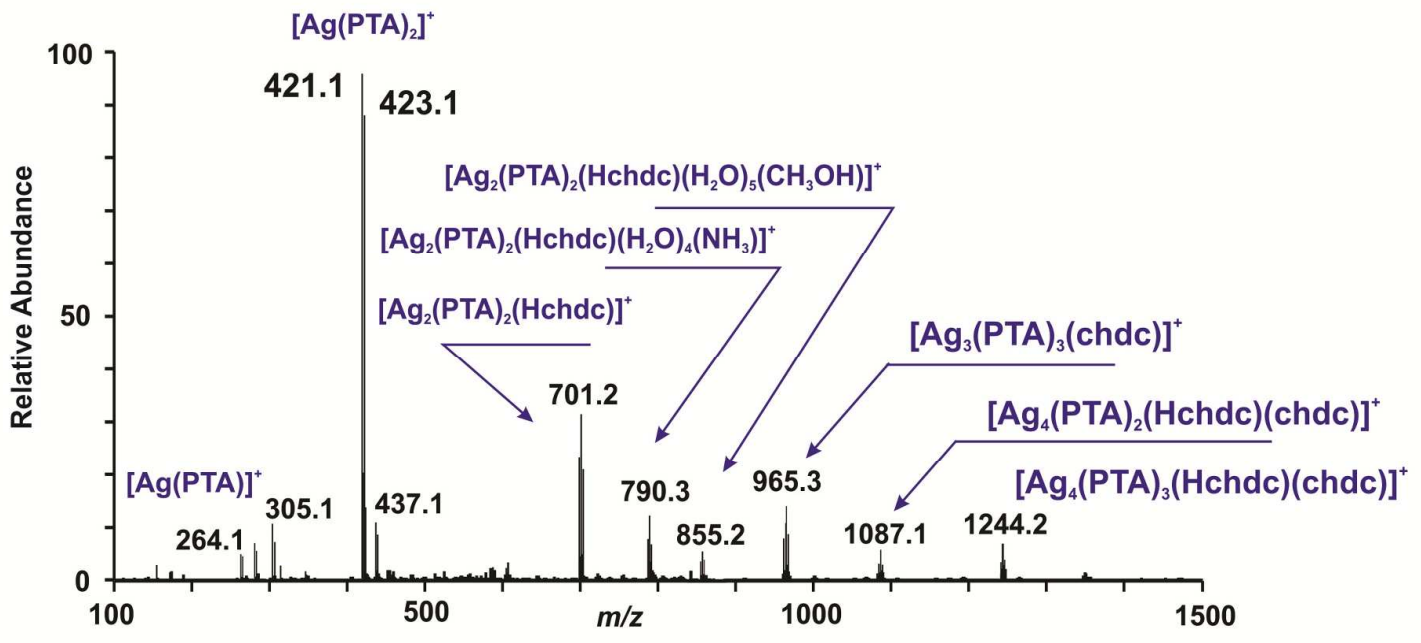

Figure S2. ESI-MS(+) spectrum of a post-reaction mixture of 2 (after 5 days) prepared according to the synthetic approach presented in Scheme 1. 


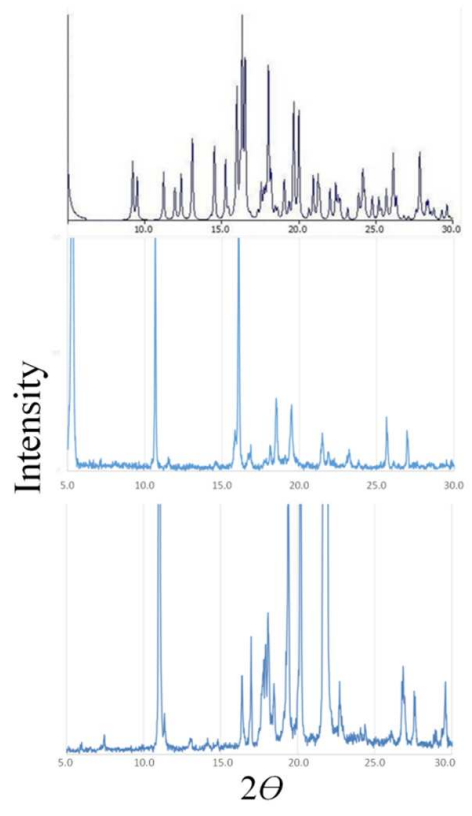

Figure S3. Comparison of PXRD patterns of compound 1 calculated from the single crystal X-ray data (top) with bulk product (central) and free Hchc acid (bottom).

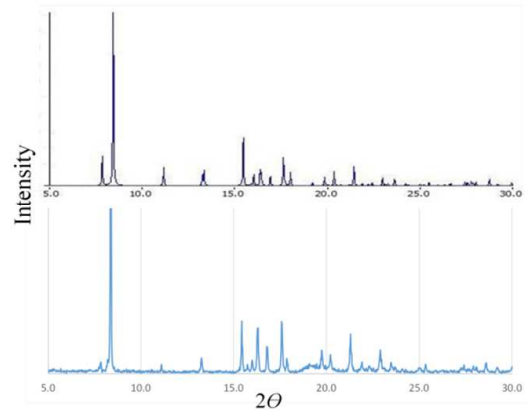

Figure S4. Comparison of PXRD patterns of compound 2 calculated from the single crystal $\mathrm{X}$-ray data (top) with bulk product (bottom).

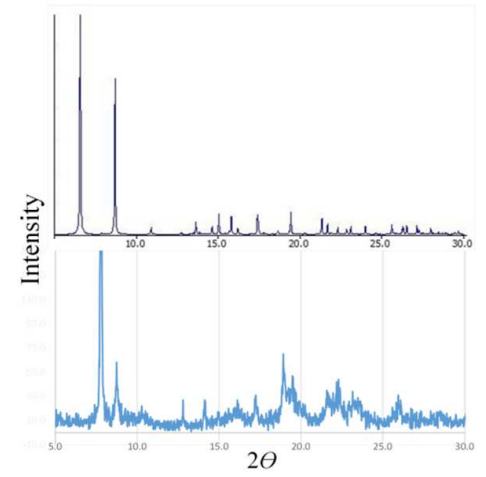

Figure S5. Comparison of PXRD patterns of compound 3 calculated from the single crystal $\mathrm{X}$-ray data (top) with bulk product (bottom). 


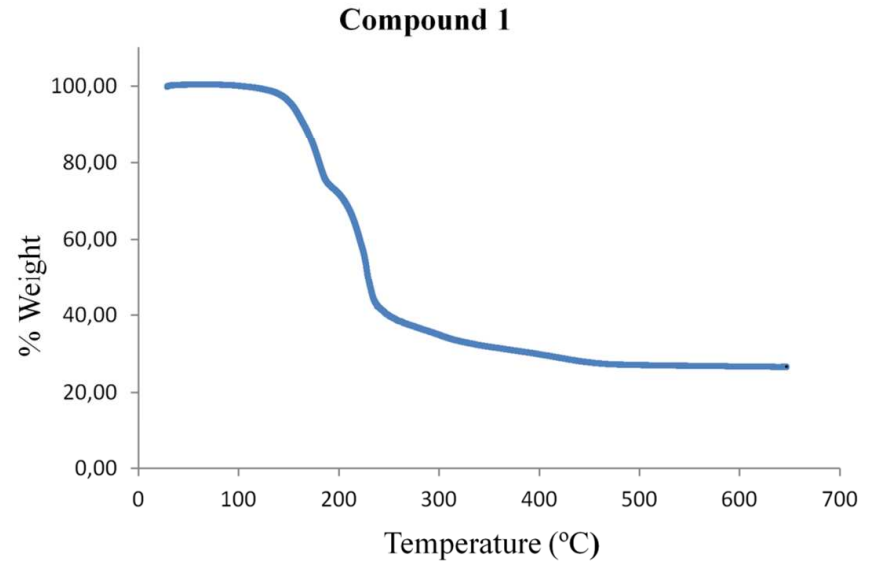

Figure S6. TGA curve of compound 1.

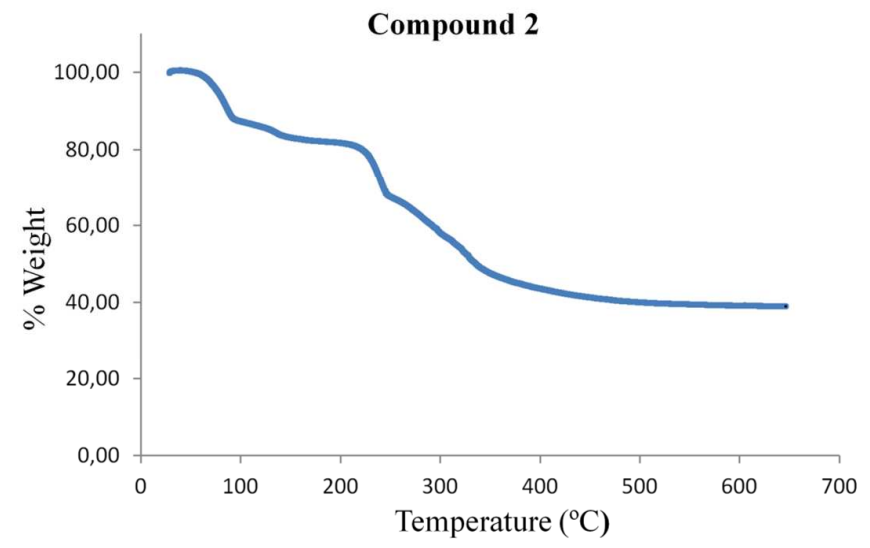

Figure S7. TGA curve of compound 2.

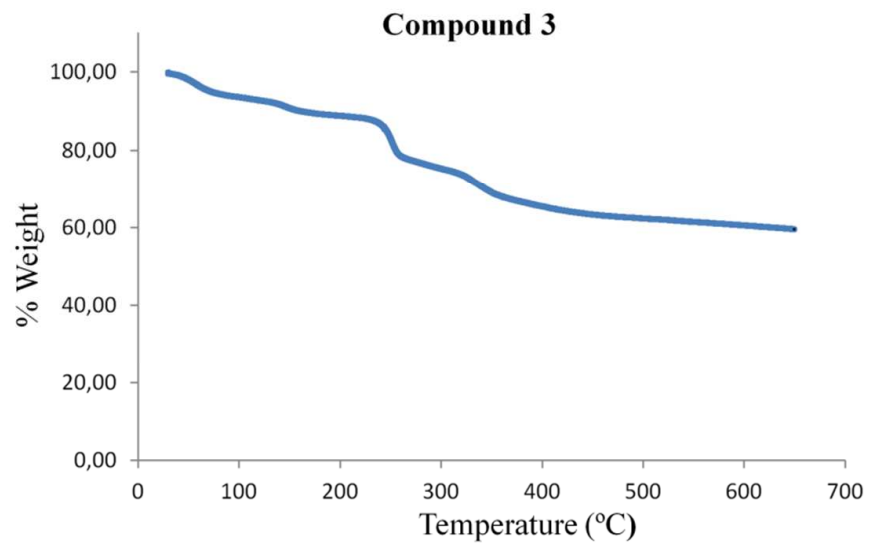

Figure S8. TGA curve of compound 3. 